\title{
Pattern of Severe Acute Maternal Morbidity in a Tertiary Care Institute
}

\author{
Narinder Kaur, ${ }^{a}$ Shreyashi Aryal ${ }^{\mathrm{a}}$
}

\begin{abstract}
:
Introduction: Maternal mortality traditionally has been the indicator of maternal health all over the world. More recently review of the cases of severe acute maternal morbidity (SAMM), also termed as "near miss obstetrics events", has been found to be a useful supplementary indicator to investigate maternal health care. Cases of near miss are those in which women present with potentially fatal complication during pregnancy, delivery, or the puerperium and survive merely by chance or by good hospital care. This study was done with the objective to analyze cases of SAMM at Lumbini Medical College Teaching Hospital (LMCTH), Nepal. Methods: A retrospective study of all cases meeting the WHO criteria for SAMM, during May 2015, was done. Cases meeting the WHO eligibility criteria for near miss cases were included in the study. Medical record of such cases in past one year was reviewed. Their sociodemographic variables, parity, gestational age, associated organ dysfunction, ICU and hospital stay, management, and fetal and maternal outcome were noted. Results: During the study period, there were total of 28 cases of SAMM and two maternal mortality out of 2735 live births. Thus rate of SAMM was $1.02 \%$, and maternal mortality rate was $0.07 \%$. Majority of patients were unbooked $(\mathrm{n}=18,64.28 \%)$ and $10(35.71 \%)$ were illiterate. Commonest causes for admission to ICU was hemorrhage $(n=10,35.71 \%)$ followed by hypertensive disorders $(n=9,32.06 \%)$, sepsis $(n=2,7.14 \%)$, and obstructed labour $(n=2,7.14 \%)$. Laparotomy was performed in six $(21.42 \%)$ women, obstetric hysterectomy in four (14.28\%), and pelvic devascularization in two (10.71\%). Conclusion: SAMM is a useful adjunct to maternal mortality to assess maternal health care. Improving facility based care and prompt referral, education of primary health care (PHC) staff can be a short term measure to quickly reduce the number of maternal deaths. Facility based monitoring and reporting of SAMM outcome is an important step for scaling up such efforts.
\end{abstract}

Keywords: maternal death • maternal mortality • morbidity • near miss • obstetric complications

\section{INTRODUCTION:}

Each year nearly 289,000 women die globally due to pregnancy associated causes. ${ }^{1}$ For each maternal death, nearly 118 women suffer from life threatening event of "severe acute maternal morbidity" (SAMM). ${ }^{2}$ SAMM is also known as "near miss" and is described as a very ill pregnant (antenatal, intrapartum or 42 days after termination

a - Lecturer, Department of Obstetrics and Gynecology

Lumbini Medical College, Palpa, Nepal

Corresponding Author:

Dr. Narinder Kaur

e-mail: dr.kaurnarinder@gmail.com

How to cite this article:

Kaur N, Aryal S. Pattern of severe acute maternal morbidity in a tertiary care institute. Journal of Lumbini Medical College. 2015;3(2):45-9. doi: 10.22502/jlmc.v3i2.72. of pregnancy) women who would have died had it not been the good luck and good care on her side., Maternal mortality is one of the important indicator of maternal health care but during the 1990s, the concept of SAMM emerged in response to the need for a more sensitive marker of quality of obstetric care., 3 The prevalence of SAMM is more in developing countries and causes are mainly hemorrhage, hypertensive disorders, sepsis, and obstructed labour, which are the same as that for maternal mortality. ${ }^{4}$ Near miss is an indicator of maternal health and maternal care at any institution. ${ }^{1,3,4}$ Good antenatal care, timely referral and diagnosis, availability of blood in time, and maintenance of asepsis can go long way in improving the SAMM. ${ }^{8}$

Systematic reviews have shown that there are many inconsistencies in classification of maternal deaths, standard definition and criteria for 
identifying SAMM, and near miss. ${ }^{4,9-11}$ In this study, World Health Organization near miss guideline was used. ${ }^{6,12}$

A survivor of a near miss event is an indicator of the quality of care provided. An audit of SAMM can help identify factors leading to maternal morbidity and its complications and assess the quality of care within the health care facility which will help in making improvements in these areas of health care.

\section{METHODS:}

This is a retrospective study done at Lumbini Medical College Teaching Hospital, Nepal which is a 700 bedded tertiary care referral center in hilly mid western Nepal. All cases who met the WHO criteria for SAMM from $1^{\text {st }}$ May 2014 to 31st of July 2015 were included in the study. ${ }^{9,13}$

Those patients were analyzed for the following information: booking, literacy and socio-economic status, gestational age, parity, disease responsible for critical illness, complication that prompted for ICU admission, number of stay days in ICU and hospital, management, requirement of blood and blood products and complications prompting referral to other centers.

Data were entered and analyzed in SPSS version 21. Results were interpreted as mean, SD and percentages, wherever applicable.

\section{RESULTS:}

During the study period, there were 2735 deliveries out of which 624 patient required lower segment caesarean section (LSCS) giving a LSCS rate of $22.8 \%$. Twenty eight $(1.02 \%)$ were admitted to ICU which met the WHO criteria for SAMM.

Table 1 shows the demographic detail of these 28 women. The mean age was 23.4 yrs ( $S D$ $=3.9$ ). Most women were of age less than 25 years and with parity less than two, a common trend in this region. Eighteen $(64.28 \%)$ of these pregnancies were unbooked and were admitted in emergency. Literacy level was low and majority was from low socio-economic group.

Table 2 summarizes the causes, occurrences, complications, and management of SAMM. Haemorrhage was the most common cause of SAMM followed by hypertensive disorders of pregnancy. Disseminated intravascular coagulation occurred in four subjects. Primary PPH was the leading cause
Table 1: Socio-demographic variables, parity and gestational age of participants

\begin{tabular}{|c|c|}
\hline Variables & n \% \\
\hline \multicolumn{2}{|c|}{ Age of mother (years) } \\
\hline $15-25$ & $19(67.85)$ \\
\hline $26-35$ & $7(25)$ \\
\hline$>35$ & $2(7.24)$ \\
\hline \multicolumn{2}{|l|}{ Parity } \\
\hline 0 & $2(7.24)$ \\
\hline 1 & $13(46.42)$ \\
\hline 2 & $8(28.57)$ \\
\hline$>2$ & $5(17.98)$ \\
\hline \multicolumn{2}{|l|}{ Gestational age } \\
\hline$<12$ weeks & $2(7.24)$ \\
\hline $13-28 \mathrm{wks}$ & 0 \\
\hline $29-36 w k s$ & $6(21.42)$ \\
\hline $37-40 w k s$ & $15(53.57)$ \\
\hline$>40 \mathrm{wks}$ & $5(17.85)$ \\
\hline \multicolumn{2}{|l|}{ Booking status } \\
\hline Booked & $10(35.71)$ \\
\hline Unbooked & $18(64.28)$ \\
\hline \multicolumn{2}{|l|}{ Literacy } \\
\hline Illiterate & $10(35.71)$ \\
\hline Literate & $18(64.27)$ \\
\hline \multicolumn{2}{|c|}{ Socioeconomic status } \\
\hline Low & $19(67.85)$ \\
\hline Middle & $9(32.15)$ \\
\hline High & 0 \\
\hline
\end{tabular}

present in $11(39.28 \%)$ patients. Table 3 shows the causes for hemorrhage and their management with blood and blood products. Blood and blood products were required in all cases of hemorrhage. Circulatory support was needed in 10 and mechanical ventilation in seven subjects. Surgical management was required in eight cases as shown in Table 2.

One woman developed deep vein thrombosis and had paresis on left side of the body. There were three women with sepsis, two were admitted within 10 days of puerperium with breathlessness and pulmonary congestion, were kept on ventilator support for 3 and 7 days respectively. The third patient was in 26 wks pregnancy with suspected meningitis and was referred outside due to unavailability of mechanical ventilator.

Total ICU stay was $<24 \mathrm{hrs}$ in two $(7.24 \%)$, 24-72 hour in $19(67.85 \%)$ and $>72$ hours in $7(25 \%)$ cases of SAMM. Two women with obstructed labour (CPD and neglected impacted shoulder presentation) were found to have referred late from 
Table 2: Study group according to WHO near miss criteria.

\begin{tabular}{|c|c|c|c|}
\hline Group & Near miss criterion & $n$ & $\%$ \\
\hline 1 & Severe post partum hemorrhage & 10 & 35.71 \\
\hline 2 & Severe preeclampsia + Hypertension & 5 & 17.78 \\
\hline 3 & Eclampsia & 4 & 14.28 \\
\hline 4 & Postpartum sepsis & 2 & 7.14 \\
\hline 5 & Obstructed labour & 2 & 7.14 \\
\hline 6 & Rupture uterus & 1 & 3.5 \\
\hline 7 & Severe complication of abortion & 1 & 3.5 \\
\hline 8 & Ruptured ectopic pregnancy & 1 & 3.5 \\
\hline 9 & Pregnancy with fever? meningitis & 1 & 3.5 \\
\hline 10 & $\begin{array}{l}\text { LSCS(Quadruplets for intraopera- } \\
\text { tive hypotention) }\end{array}$ & 1 & 3.5 \\
\hline \multicolumn{2}{|c|}{ Total number admitted to ICU (N) } & 28 & 100 \\
\hline \multicolumn{4}{|c|}{ Critical interventions } \\
\hline 11 & Laparatomy & 6 & 21.42 \\
\hline 12 & Interventional radiology & 0 & 0 \\
\hline 13 & Use of blood and blood products & 12 & 39.28 \\
\hline \multicolumn{4}{|c|}{ Life threatening conditions } \\
\hline 14 & Cardiovascular dysfunction & 10 & 35.71 \\
\hline 15 & Respiratory dysfunction & 7 & 25 \\
\hline 16 & Renal dysfunction & 1 & 3.5 \\
\hline 17 & $\begin{array}{l}\text { Coagulation/hematological } \\
\text { dysfunction }\end{array}$ & 4 & 14.28 \\
\hline 18 & Hepatic dysfunction & 0 & 0 \\
\hline 19 & Neurological dysfunction & 1 & 3.5 \\
\hline 20 & Uterine dysfunction(hysterectomy) & 4 & 14.28 \\
\hline 21 & $\begin{array}{l}\text { Devascularization, internal iliac } \\
\text { ligation, uterine and ovarian artery } \\
\text { ligation, B-Lynch suture }\end{array}$ & 3 & 10.7 \\
\hline
\end{tabular}

Table 3: Causes of hemorrhage and requirement of blood and blood products $(N=28)$

\begin{tabular}{lc}
\hline Cause & $\boldsymbol{n}(\%)$ \\
\hline Primary PPH & $11(39.28)$ \\
\hline Uterine atony & $7(25)$ \\
\hline Cervical laceration and broad ligament hematoma & $1(3.50)$ \\
\hline Cervical laceration extending into lower segment & $1(3.5)$ \\
\hline Cervical and vaginal laceration & $1(3.5)$ \\
\hline Uterine rupture & $1(3.5)$ \\
\hline Other causes & \\
\hline Ruptured ectopic pregnancy & $1(3.5)$ \\
\hline Inevitable abortion & $1(3.5)$ \\
Blood and blood products transfused & \\
\hline 1 - 4 units whole blood & $4(14.28)$ \\
$\quad \leq 4$ fresh frozen plasma (FFP) & $2(7.14)$ \\
$\quad \leq 8$ FFP + cryopecipitate & $2(7.14)$ \\
$\leq 8$ FFP + platelets rich plasma & $1(3.5)$ \\
\hline 5 - 8 FFP & $2(7.5)$ \\
\hline 8 FFP & $1(3.5)$ \\
\hline
\end{tabular}

health institutes in the periphery. There were two maternal mortality during this period which were both unbooked and referred cases of eclampsia and obstructed labour leading to PPH and DIC.

Regarding the neonatal outcome amongst women with SAMM, there were 3 stillbirths and two neonatal deaths. During that period the rate of perinatal mortality was $1.82 / 1000$. Nine babies required NICU admission, six for prematurity, one for meconium aspiration and two for neonatal asphyxia.

One woman amongst SAMM had acute kidney injury following severe $\mathrm{PPH}$ and hysterectomy and was referred to other centre for dialysis. One antenatal woman with acute respiratory distress syndrome was referred for the want of ventilator support.

\section{DISCUSSION:}

Progress in reduction of maternal mortality has been slow. Over 1000 women still die from pregnancy related causes around the world and vast majority of these deaths occur in developing countries. ${ }^{10}$ Severe obstetric morbidity and its relation to mortality may be a more sensitive measures of pregnancy outcome than mortality alone., $3,7,9,13$ Including SAMM in maternal death audit increases the rapidity with which health system problems can be identified. But the criteria currently used to identify a near miss vary greatly. ${ }^{1,4,6,12,14}$ There is a clear need to set uniform criteria to classify patients as SAMM. ${ }^{9,15}$

Comparing the rate over time and across region, it is clear that different approaches are needed to lower the rate of near miss and that interventions must be developed with the local context in mind. ${ }^{9,13}$ The incidence of SAMM ranges from 0.07 to $8.23 \%$ and the case fatality ratio from 0.02 to $37 \% \cdot{ }^{16}$ In the present study, occurrence of SAMM was $1.02 \%$ and maternal mortality rate was $0.07 \%$ (70/100000) respectively. In Nepal maternal mortality is reported as 229/100000 in 2008-2009. ${ }^{17}$ Low maternal mortality in our institute may be due to a small size reported from a single institution only. Comparable incidence of SAMM are reported by other institutions in Nepal as $2.23 \%$ and $3.5 \%{ }^{18,19}$ Hemorrhage and hypertensive disorder in pregnancy are the most common cause of direct obstetric deaths being disproportionately higher among the poor, less educated, at the extremes of reproductive period and 
the women with higher parity. ${ }^{4,13}$ This is the same as reported in the current series. Worldwide, the leading causes of severe morbidity are hemorrhage, pregnancy related hypertension, sepsis, and obstructed labour. ${ }^{1,2,-6,9,13}$ In current study, findings are comparable being $46.42 \%, 32.06 \%, 10.62 \%$, and $7.14 \%$ respectively.

Regardless of geographical factors, hemorrhage is the largest contributor accounting for one-fifth to half of the cases. ${ }^{420-22}$ Hypertensive disease and its consequences account for $10 \%$ to $45 \%$ of cases of SAMM. ${ }^{21,22,26}$ In our series hemorrhage and hypertensive disorders were responsible for $46.42 \%$ and $35.14 \%$ respectively. The reported incidence of haemorrhage in this study (35.71\%) is higher than that reported by Upadhyaya I. et al. $(14.6 \%)$ but comparable to that reported by Shrestha NS. et al. (41.66\%) in other institutes in Nepal. ${ }^{18,19}$ However the incidence of hypertensive disorders were higher in the study by Upadhyaya et al. (50\%) as compared to $32.06 \%$ in our study. ${ }^{18}$

Good antenatal services with aggressive management of preeclampsia, particularly during labour are to be encouraged. The provision of an ICU for eclamptic patients especially in certain designated areas of labour suits with excellent nursing care would be helpful. ${ }^{23}$ Similarly hemorrhage should be diagnosed in time and managed aggressively.

Untoward are the result of too little or too late management. Good blood bank services are necessary round the clock; severe morbidity usually results, for the lack of availability of blood and blood products, delayed referral and delayed diagnosis. Shortage of MICU beds and lack of high dependency units in obstetrics departments are responsible for high mortality ratio. ${ }^{24}$ Strengthened health system and effective maternal health care particularly with acute pregnancy related complications are considered the key factors for reducing maternal mortality. ${ }^{21}$

Basic antenatal care cannot be over emphasized as ample evidence shows that antenatal follow up decreases a woman's risk when it comes to labour and delivery. ${ }^{12,25}$ In this study majority of the women were unbooked (64.28\%). This emphasizes the need of antenatal counseling. Screening for anemia and complicating diseases during ANC, hygiene during labour, presence of skilled birth attendant and active management of third stage of labour are the basic requirement advocated by WHO. ${ }^{8,13}$ Some factors for late presentation include awareness, level of weak referral system, financial constrains, gender discrimination, constrains on mobility, health seeking behavior during illness and acceptable norms related to physiologic phenomenon i.e. menstruation, pregnancy and child birth. Additionally the absence of medical facilities also results in amplified morbidity and mortality in these women,same is seen in the present series. ${ }^{26}$

Poor antenatal care, coverage and awareness, delayed diagnosis of severe morbidity, untimely often delayed referral and transfer and unavailability of resources might have been the cause of avoidable severe maternal morbidity and mortality in our study as $64.28 \%$ were unbooked and admitted in emergency. Most maternal morbidities and mortalities could have been avoided with the help of government funded policies including early referrals, quick, efficient and well equipped transport facilities, availability of adequate blood and blood products and promoting safe motherhood.

\section{CONCLUSION:}

The leading causes of severe maternal morbidity in this institute were hemorrhage and hypertensive disorders of pregnancy. It is a good indicator for designing, monitoring, follow-up and evaluation of safe motherhood. Regular auditing on regular basis for improvement in management is necessary. Maternal mortality and SAMM can be reduced by meticulous adaptation of safe motherhood initiative, provision of separate ICU for obstetric patients, early assessment and aggressive interventions through team management involving obstetrician, anesthetist, other specialties as and when required. Efforts geared towards improvements in the management of near miss morbidities would definitely go a long way in reducing the present maternal mortality ratio and long term pregnancy complications.

\section{REFERENCES:}

1. World Health Statistics 2014: Fact Sheets. Geneva: World Health Organization; 2014.

2. Waterstone M, Bewley S, Wolfe C. Incidence and predictors of severe obstetric morbidity: case-control study. BMJ. 2001;322(7294):1089-93.

3. Stones W, Lim W, Al-Azzawi F, Kelly M. An investigation of maternal morbidity with identification of life threatening 'near miss' episodes. Health Trends. 1991;23(1):13-5.

4. Mantel GD, Buchmann E, Rees H, Pattison RC. Severe acute maternal morbidity: a pilot study of a definition for near-miss. Br J Obstet Gynaecol. 1998; 105(9):985-90. 
5. Khan KS, Wojdyla D, Say L, Gulmezoglu AM, Van look PF. WHO analysis of causes of maternal deaths: a systematic review. Lancet. 2006;367(9516):1066-74. doi: 10.1016/ S0140-6736(06)68397-9.

6. Say L, Souza JP, Pattison RC, WHO working group on Maternal Mortality and Morbidity classifications. Maternal near miss--towards a standard tool for monitoring quality of maternal health care, Best Pract Res Clin Obstet Gynaecol. 2009;23(3):287-96. doi: 10:1016/j.bpobgn.2009.1.007.

7. Lewis G. Confidential Enquiry into Maternal and Child Health- Improving care for mothers, babies and childrenWhy Mothers Die 2000-2002, Executive Summary and Key Findings- The Sixth Report of the Confidential Enquiries into Maternal Deaths in the United Kingdom. London; RCOG Press. 2004.

8. Lazarus JV, Lalonde A. Reducing postpartum hemorrhage in Africa. Int J Gyanecol Obstet. 2005;88(1):89-90.

9. Tuncalp O, Hindin MJ, Souza JP, Chou D, Say L. The prevalence of maternal near miss: a systematic review. BJOG. 2012;119(6):653-61.

10. Moody J. Confidential Enquiry into Maternal and Child Health- Improving care for mothers, babies and childrenWhy Mothers Die 2000-2003, Executive Summary and Key Findings- Report of the Confidential Enquiries into Maternal Deaths in the United Kingdom. London; RCOG Press. 2004.p.234-4.

11. Gandhi MN, Wiez T, Ronsmans C. Severe Acute Maternal Morbidity in Rural South Africa. Int. J Gynaecol Obstet. 2004; 87(2):180-7.

12. Pattison R, Say L, Souza JP, Broek NV, Rooney C, WHO Working Group on Maternal Mortality and Morbidity Classifications. WHO maternal death and near-miss classification. Bulletin of the World Healthh Organization 2009;87:p.734. doi: 10.2471/BLT.09.071001.

13. World Health Organization, Department of Reproductive Health and Research. Evaluating the quality of care for severe pregnancy complications: The WHO near-miss approach for maternal health. WHO guide; Geneva: 2011.

14. World Health Organization. Maternal Mortality in 2005: Estimates developed by WHO, UNICEF, UNFPA and The World Bank. Switzerland; World health organization; 2010. p.15-6.

15. Ostermann M, Raimundo M, Williams A, Whitely C, Beale R. Retrospective analysis of outcome of women with breast or gynaecological cancer in the intensive care unit. JRSM Short Rep. 2013 Jan;4(1):2. doi: 10.1258/ shorts.2012.012036.

16. Minkauskiene M, Nadisauskiene R, Padaiga Z, Makari S. Systematic review on the incidence and prevalence of severe maternal morbidity. Medicina (Kaunas). 2004;40(4):299309.

17. Barnett S, Sharma SK, Poudel P, Chitrakar SR, K.C NP, Hulton L. Nepal maternal mortality and morbidity study 2008/09. Kathmandu: Family Health Division, Government of Nepal; 2010.

18. Upadhyaya I, Chaudhary P. Severe Acute Maternal Morbidity and Intensive care in Paropakar Maternity and Womens' Hospital. NJOG. 2013;8(2):38-41.

19. Shrestha NS, Saha R, Karki C. Near miss maternal morbidity and maternal mortality at Kathmandu Medical College Teaching Hospital. Kathmandu Univ Med J. 2010;8(30):222-6.

20. Bouvier-Colle MH, Salanave B, Ancel PY, Varnoux N, Fernandez H, Papiernik E, et al. Obstetric patients treated in intensive care units and maternal mortality. Regional team for the survey. Eur J Obstet Gyaecol Reprod Biol. 1996;65(1): 121-5.

21. Prual A, Bouviier-Colle MH, de Bernis L, Breart G. Severe maternal morbidity from direct obstetric causes in West Africa: incidence and case fatality rates. Bull World Health Organ. 2000;78(5):593-602.

22. Brace V, Penney G, Hall M. Quantifying severe maternal morbidity: a Scottish population study. Br J Obstet Gynaecol. 2004;111(5):481-4.

23. Wilson RE, Salihu HM. The paradox of obstetrics 'near misses": converting maternal mortality into morbidity. Int J Fertil Womens Med. 2007;52(2-3):121-7.

24. Bibi S, Memon A, Sheikh JM, Qureshi Ali. Severe acute maternal morbidity and intensive care in a public sector university hospital of Pakistan. J Ayub Med Coll Abbottabad. 2008:20(1):109-12.

25. The mother-baby package: WHO's guide to saving women's and infant's lives. Safe Mother. 1994;15:4-7.

26. Ostermann M, Raimundo M, Williams A, Whitely C, Beale R. Retrospective analysis of outcome of women with breast or gynaecological cancer in the intensive care unit. JRSM Short Rep. 2013 Jan;4(1):2. doi: 10.1258/ shorts.2012.012036. 